Check for updates

Cite this: New J. Chem., 2021, 45,5808

Received 17th January 2021, Accepted 16th February 2021

DOI: 10.1039/d1nj00275a

rsc.li/njc

\section{Synthesis, and the optical and electrochemical properties of a series of push-pull dyes based on the 4-(9-ethyl-9H-carbazol-3-yl)-4-phenylbuta- 1,3-dienyl donor $\dagger$}

\author{
Corentin Pigot, (D) *a Guillaume Noirbent, (D) ${ }^{a}$ Thanh-Tuân Bui, (DD ${ }^{b}$ \\ Sébastien Péralta, (DD ${ }^{b}$ Sylvain Duval, (D) ${ }^{c}$ Didier Gigmes, (D) ${ }^{a}$ Malek Nechab (D) a and \\ Frédéric Dumur (iD *a
}

\begin{abstract}
A series of twelve dyes based on the 4-(9-ethyl-9H-carbazol-3-yl)-4-phenylbuta-1,3-dienyl donor were prepared with electron acceptors varying in their structures but also in their electron-withdrawing ability. For specificity, a butadienyl spacer was introduced between the donor and the acceptor to both lower the bandgap and furnish dyes with high molar extinction coefficients. The different dyes A-N were characterized using various techniques including UV-visible absorption and fluorescence spectroscopy, and cyclic voltammetry. All dyes showed an intense intramolecular charge transfer band located in the visible range. To further investigate the optical properties of the twelve dyes, their solvatochromism was investigated in twenty-three solvents of different natures, enabling linear correlations to be obtained on different polarity scales such as the Taft, Reichardt and Catalan scales. To support the experimental results, the optical properties were compared with those theoretically determined.
\end{abstract}

\section{A Introduction}

During the past decades, organic dyes have attracted a great deal of interest from both the academic and industrial communities due to the numerous applications in which these structures can be used. Notably, organic dyes can be employed as singlet or triplet emitters for organic light-emitting diodes ${ }^{1-3}$ as light-absorbing materials for organic photovoltaics (OPVs), ${ }^{4-6}$ as chromophores for non-linear optical applications, ${ }^{7-9}$ as dyes for various biological applications including cancer phototherapy or biological labelling, ${ }^{10,11}$ as photoinitiators of polymerization, ${ }^{12-20}$ and as photoredox catalysts for organic transformations or hydrogen production. ${ }^{21-24}$ Recently, significant efforts have been devoted to replace organic dyes by push-pull dyes in photopolymerization because the absorption spectra of push-pull dyes are easy to tune. ${ }^{25-32}$ For many of the abovementioned applications, the possibility to design metal-free dyes is especially attractive, addressing the toxicity issue often raised by the use of transition metal

\footnotetext{
${ }^{a}$ Aix Marseille Univ., CNRS, ICR UMR7273, F-13397 Marseille, France.

E-mail: pigotcorentin2@gmail.com, frederic.dumur@univ-amu.fr

${ }^{b}$ CY Cergy Paris Université, LPPI, F-95000 Cergy, France

${ }^{c}$ Université de Lille, CNRS, Centrale Lille, ENSCL, Univ. Artois,

UMR 8181 - UCCS - Unité de Catalyse et Chimie du Solide, F-5900o Lille, France $\dagger$ Electronic supplementary information (ESI) available. See DOI: 10.1039/ d1nj00275a
}

complexes. ${ }^{33-36}$ For the design of organic molecules strongly absorbing in the visible range and displaying molar extinction coefficients on par with those of the transition metal complexes, push-pull dyes incorporating an electron donor connected to an electron acceptor by means of a $\pi$-conjugate spacer are the most obvious candidates and the most straightforward route to get molecules with high molar extinction coefficients. ${ }^{37-39}$ Indeed, the position of the intramolecular charge transfer (ICT) band can be easily tuned by modifying both the strength of the electron donating and the electron accepting abilities of the two groups attached at both ends of the $\pi$-conjugated spacer. ${ }^{40-43}$ This strategy is notably extremely useful to red-shift the ICT bands and thus reduce the HOMO-LUMO gap (where HOMO and LUMO respectively stands for highest occupied molecular orbital and lowest unoccupied molecular orbital). ${ }^{44-47}$ Additionally, the molar extinction coefficient can be drastically increased by elongating the $\pi$-conjugated spacer between the donor and the acceptor as a result of an improvement of the oscillator strength. ${ }^{47-49}$ However, elongation of the $\pi$-conjugation in these structures is not an easy task, as exemplified with the synthesis of 3-(9-alkyl-9H-carbazol-3-yl)acrylaldehydes. Indeed, for this aldehyde, only three syntheses are reported in the literature. ${ }^{50-54}$ In fact, carbazole is a remarkable electron donor exhibiting a relatively low oxidation potential, and good thermal stability and this polyaromatic structure can also be easily chemically modified. ${ }^{53,54}$ Carbazole is also a cheap compound 


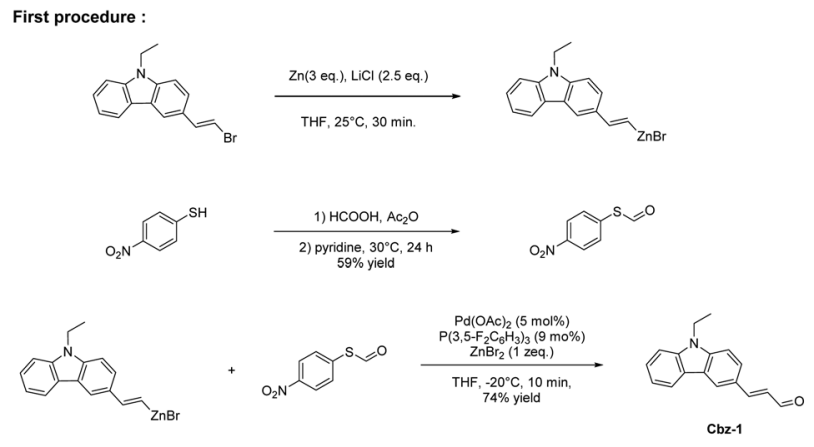

Second procedure :

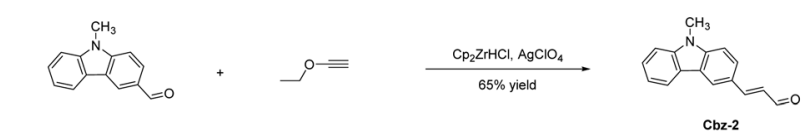

Third procedure :
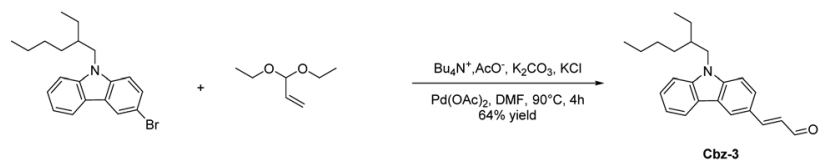

Scheme 1 Synthetic route to 3-(9-alkyl-9H-carbazol-3yl)acrylaldehydes $\mathbf{C b z}-\mathbf{1}-\mathbf{C b z}-\mathbf{3}$

and so this structure was extensively used in Organic Electronics, with applications ranging from fluorescence emitters to host materials for OLEDs. ${ }^{55-58}$

While coming back to the synthesis of 3-(9-alkyl-9Hcarbazol-3-yl)acrylaldehydes, the three procedures reported in the literature are based on metal-catalysed syntheses, namely the palladium-catalysed formylation of an alkenylzinc intermediate using $S$-(4-nitrophenyl)thioformate to introduce the aldehyde group for the synthesis of $\mathbf{C b z}-\mathbf{1},{ }^{59}$ the hydrozirconation homologation method of Maeta and Suzuki for the synthesis of Cbz- ${ }^{60}$ or the Pd-catalysed coupling reaction of acrolein diethyl acetal on a brominated carbazole for the synthesis of $\mathbf{C b z}-\mathbf{3}^{61-63}$ (see Scheme 1). If large scale syntheses are required, these reactions are not adapted, requiring the use of multistep syntheses taking recourse to expensive catalysts, dry solvents and imposing a controlled atmosphere to proceed. Simpler synthetic methods are thus actively being researched. Recently, several studies were devoted to elaborate acrolein derivatives starting from benzophenone derivatives. This strategy was notably successfully applied to the synthesis of Michler's aldehyde starting from Michler's ketone. ${ }^{64,65}$ More recently, new benzophenone derivatives were also converted to their aldehyde analogues, ${ }^{66-71}$ furnishing dyes exhibiting a strong positive solvatochromism. ${ }^{72,73}$

In light of these results, a hybrid carbazole-based benzophenone Cbz-BP in which the electron donating ability is reinforced by the presence of the carbazole moiety has been converted to its aldehyde analogue $\mathbf{C b z}-\mathbf{3}$. The approach used to access this extended electron donor is unprecedented for carbazole derivatives. This aldehyde part allowed an affordable synthesis of 12 dyes $\mathbf{A}-\mathbf{N}$ differing by the electron acceptors and containing two isolated isomers: D/I (see Fig. 1). It must be noticed that this strategy consisting in generating an extended carbazole-based electron
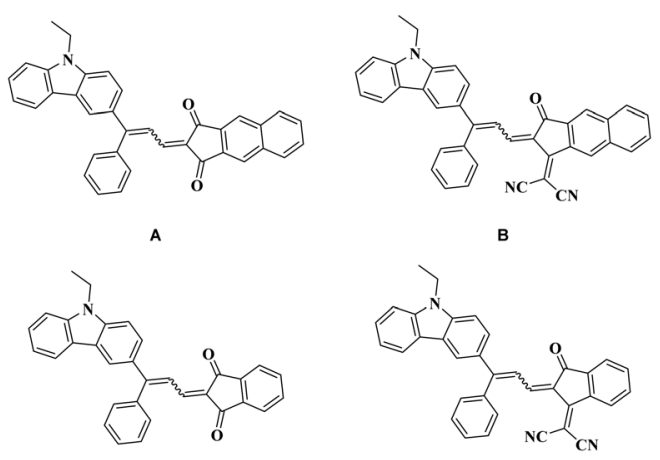

C/D
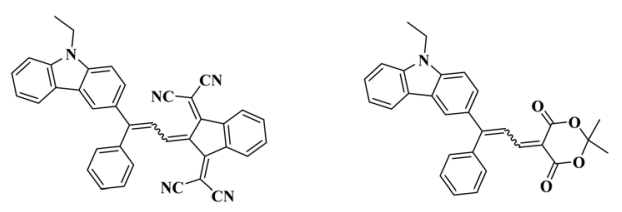

$\mathbf{F}$
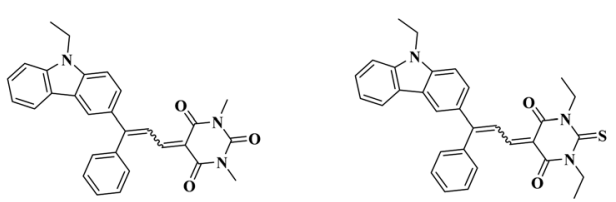

H/I

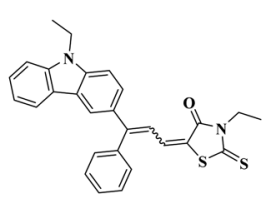

$\mathbf{J}$

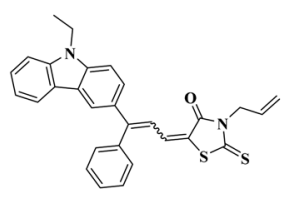

K

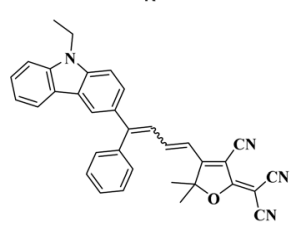

L

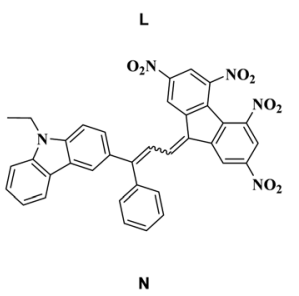

Fig. 1 Chemical structures of dyes $\mathbf{A}-\mathbf{N}$.

donor by preparing first a carbazole-benzophenone adduct later converted as an acrylaldehyde is unprecedented. To the best of our knowledge, no such 3,3-diphenylacrylaldehyde derivative has been previously reported in the literature. However, the conversion of a carbazole-benzophenone adduct as an alkene has recently been reported in the literature. ${ }^{74}$ The different dyes were seen by a strong absorption extending over the visible range. These dyes were characterized using various techniques including UV-visible absorption and fluorescence spectroscopy and cyclic voltammetry. Theoretical calculations were also carried out to get a deeper insight into the electronic transitions involved in the optical transitions. Finally, solvatochromism of the 12 dyes was examined on several solvent polarities scales and linear correlations could be obtained using the Kamlet-Taft, Reichardt and Catalan empirical models. 


\section{B Results and discussion}

\section{B1. Synthesis of the dyes}

The extended aldehyde Cbz-BP has been synthesized in three steps starting from 9-ethyl-9H-carbazole. By performing a FriedelCrafts reaction with benzoyl chloride in the presence of aluminum chloride, (9-ethyl-9H-carbazol-3-yl)(phenyl)methanone could be prepared in $84 \%$ yield. Addition of methylmagnesium iodide followed by a dehydration reaction furnished 9-ethyl-3-(1phenylvinyl)-9H-carbazole in almost quantitative yield (see Scheme 2). Formylation of the alkene by a Vilsmeier-Haack reaction gave $\mathbf{C b z}-\mathbf{B P}$ as a mixture of s-cis/s-trans isomers that could not be separated via column chromatography. All attempts of iodine-catalyzed thermal cis/trans isomerization in toluene did not allow the modification of the ratio between isomers. ${ }^{75}$ If no structural determination was carried out to identify which isomer was the main product, a 2:1 ratio could be found on the proton NMR spectrum of Cbz-BP. Interestingly, modification of the reaction time during the Vilsmeier-Haack reaction did not modify the ratio between isomers. Consequently, this mixture of isomers was subsequently used for the synthesis of the different dyes. Besides, in order to investigate the potential influence of the isomerization onto the optical properties, one of the two isomers could be obtained in almost pure form but in small quantity by crystallisation at $-20{ }^{\circ} \mathrm{C}$ in a mixture of THF/pentane solvents.

Finally, eleven of the twelve dyes of the series were prepared via a Knoevenagel reaction carried out under basic conditions. Except for dyes $\mathbf{B}$ and $\mathbf{E}$ for which diisopropylamine (DIPA) was used instead of piperidine, all dyes could be obtained with reaction yields ranging from 78 to $92 \%$ (see Scheme 3 ). In the case of dyes $\mathbf{B}$ and $\mathbf{E}$, the choice of DIPA as the base was motivated by recent results reported in the literature mentioning a nucleophilic attack of secondary amines on the cyano groups of EA5, inducing a cyclization reaction and producing azafluorenone derivatives. ${ }^{76-80}$ However, piperidine could be used for the synthesis of dye $\mathbf{M}$, no nucleophilic attack of amine being reported at present in the literature for EA11. Finally, dye F was prepared by using a specific procedure. Indeed, due to the
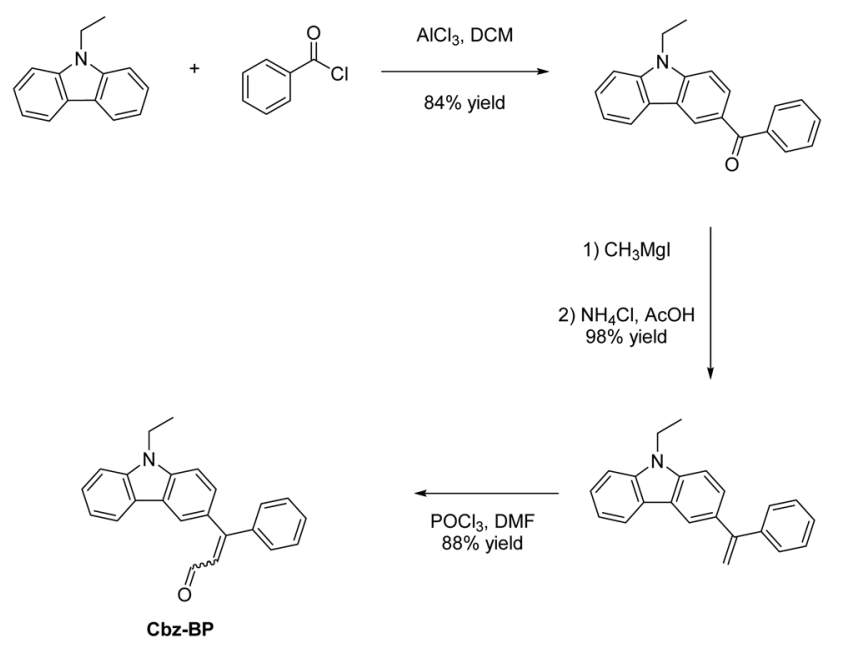

Scheme 2 Synthetic route to $\mathbf{C b z}-\mathbf{B P}$.
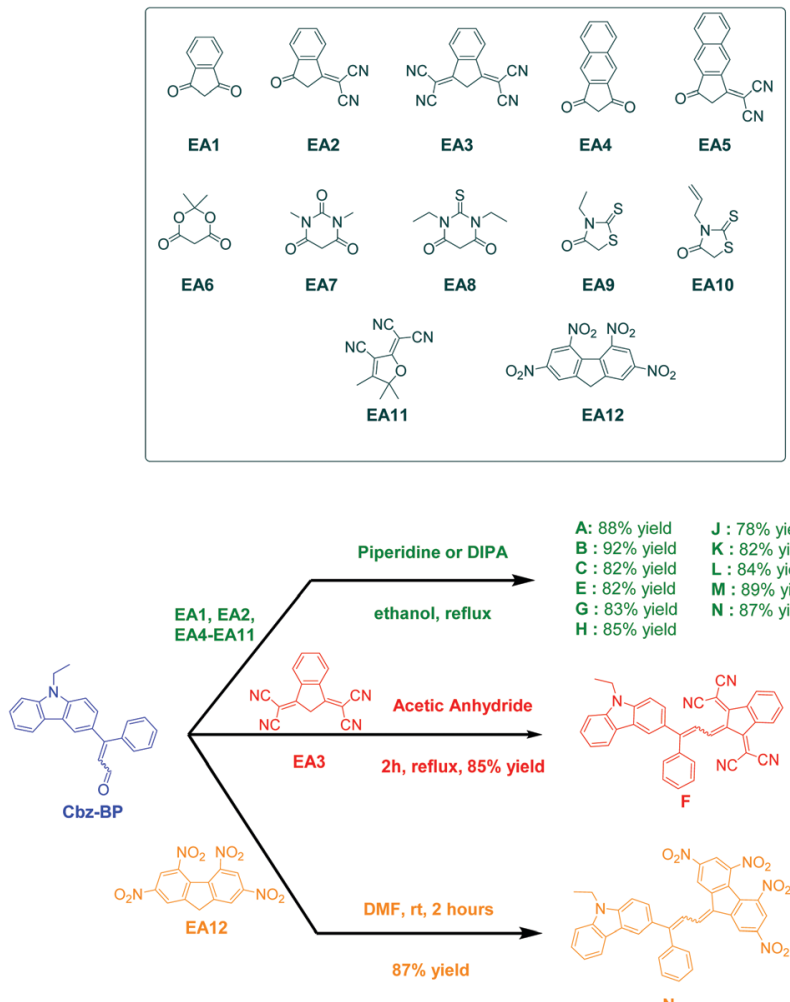

A: $88 \%$ yield $\mathrm{J}: 78 \%$ yield $B: 92 \%$ yield $K: 82 \%$ yield $\begin{array}{ll}\mathrm{C}: 82 \% \text { yield } & L: 84 \% \text { yield } \\ \mathrm{E}: 82 \% \text { yield } & \mathrm{M}: 89 \% \text { yield }\end{array}$ $\mathrm{G}: 83 \%$ yield $\mathrm{N}: 87 \%$ yield G : $83 \%$ yield

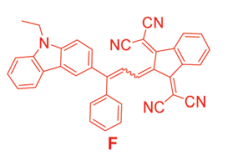

Scheme 3 Synthetic route to dyes $\mathbf{A}-\mathbf{N}$

remarkable stability of the EA3 anion in basic conditions, no condensation reaction can occur. To circumvent this problem, the condensation of Cbz-BP and EA3 in acetic anhydride furnished dye $\mathbf{F}$ in $85 \%$ yield.

In the case of symmetric electron acceptors (EA1, EA3, EA4, EA6, EA7, EA8 and EA12), the corresponding dyes (A, C, F-J and $\mathbf{N})$ were obtained as a mixture of s-cis and s-trans isomers. Conversely, a more complex situation was found for dyes prepared with EA2, EA5, EA9, EA10 and EA11, since in the complement of a s-cis/s-trans mixture, the different electron acceptors could adopt two different orientations so that a mixture of 4 isomers could be theoretically obtained in these cases (see Fig. 2). Besides, the steric hindrance induced by the use of asymmetric electron acceptors such as EA2 and EA5 certainly favour an orientation over the other. It has to be noticed that among the twelve electron acceptors issued in this study, EA2 ${ }^{81}$ EA3,${ }^{82}$ EA4,${ }^{83}$ EA5,${ }^{76}$ EA11 $^{84}$ and EA12 ${ }^{85}$ had to be prepared.

Interestingly, two isomers ( $\mathbf{D}$ and $\mathbf{I}$ ) could be isolated in pure form. Indeed, due to the marked insolubility of one of the isomers of dyes I, these could be easily separated from its mixture via precipitation. Conversely, in the case of dye D (which is a pure isomer of $\mathbf{C}$ ), this latter was obtained by opposing the isolated isomer of Cbz-BP to EA1 under basic conditions. Finally, due to the exceptional electronwithdrawing ability of EA12, a spontaneous deprotonation can occur in highly polar solvents such as DMF. Therefore, $\mathbf{N}$ could be prepared at room temperature in DMF, without using a base, and obtained as a precipitate upon addition of pentane 

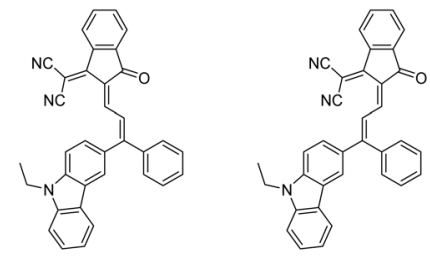

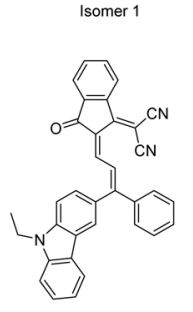

Isomer

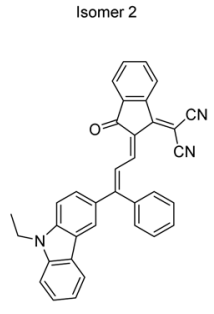

Isomer 4
Fig. 2 The four possible isomers when asymmetric electron acceptors are used.

to the reaction media. Dye $\mathbf{N}$ was isolated in the pure form by filtration, in $87 \%$ yield.

\section{B2. Optical properties}

All dyes showed good solubility in chloroform so that a comparison of their optical properties could be established. A summary of the optical properties is provided in Table 1 and Fig. 3 and 4. As shown in the Fig. 3, a severe variation of the absorption maxima with the electron-withdrawing ability of dyes A-N could be detected. Thus, absorption maxima ranging from $475 \mathrm{~nm}(\mathbf{K})$ to $587 \mathrm{~nm}(\mathbf{N})$ and $610 \mathrm{~nm}$ (B) were found. Position of the ICT bands undergo a redshift following the order of the electron acceptor strength. Notably, comparison of the absorption maxima between $\mathbf{A}$ and $\mathbf{C}$ revealed the elongation of the indane-1,3-dione-based acceptor EA4 to red-shift the absorption of $\mathbf{A}$ by $c a .30 \mathrm{~nm}$ compared to that determined for $\mathbf{C}$ comprising EA1 as the acceptor. Interestingly, a superimposition of the absorption spectra of $\mathbf{A}$ and $\mathbf{J}$ could be
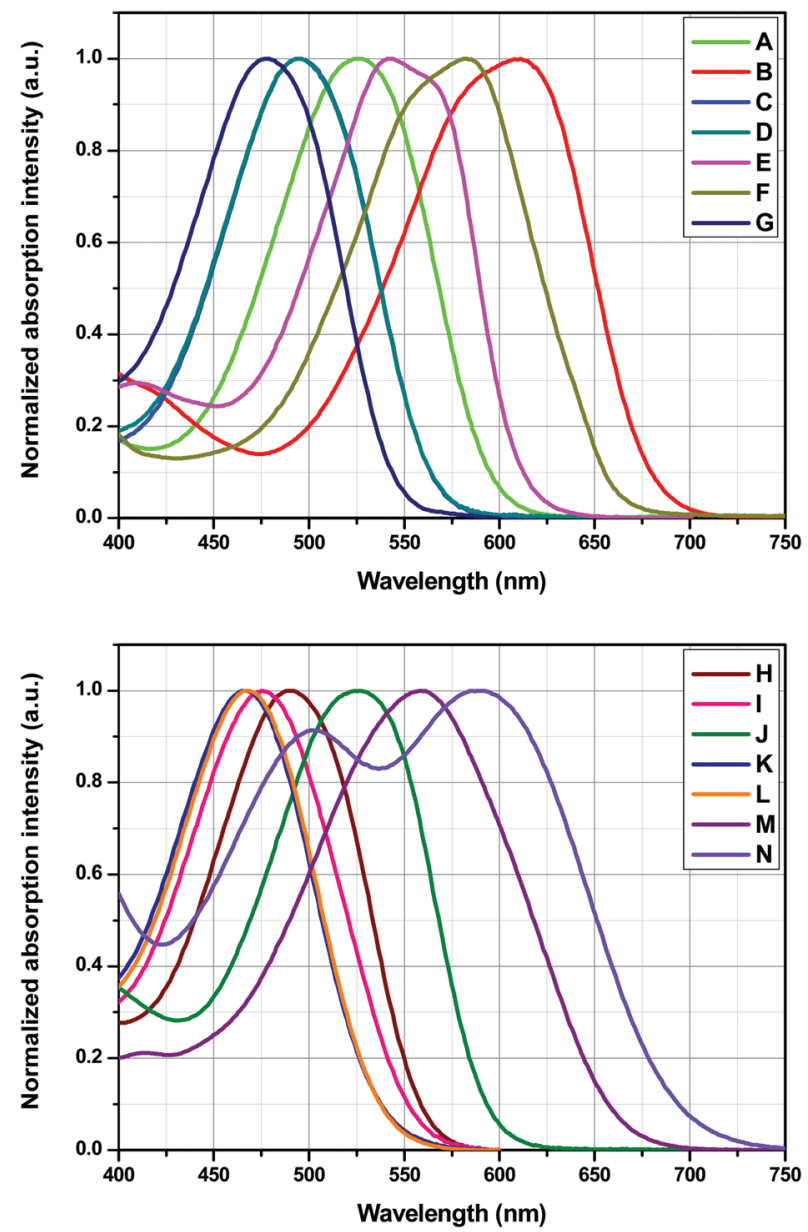

Fig. 3 Normalized UV-visible absorption spectra of dyes $\mathbf{A}-\mathbf{N}$ in chloroform.

clearly evidenced, demonstrating that the electron-withdrawing abilities of $1 H$-cyclopenta[ $[b]$ naphthalene-1,3(2H)-dione EA4 and 1,3-diethyl-2-thioxodihydropyrimidine-4,6(1H,5H)-dione EA8 were

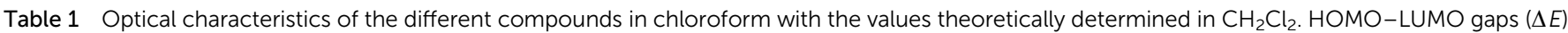
are also shown in this table

\begin{tabular}{|c|c|c|c|c|c|c|c|}
\hline Compounds & $\mathbf{A}$ & B & $\mathbf{C}$ & D & $\mathbf{E}$ & $\mathbf{F}$ & $\mathbf{G}$ \\
\hline$\lambda_{\exp }(\mathrm{nm})$ & 525 & 610 & 495 & 495 & 575 & 583 & 479 \\
\hline$\lambda_{\text {theo }}(\mathrm{nm})$ & 495 & 559 & 475 & - & 542 & 554 & 470 \\
\hline$\varepsilon_{\exp }\left(\mathbf{M}^{-1} \mathrm{~cm}^{-1}\right)$ & 42600 & 57750 & 36400 & 35900 & 40300 & 37700 & 35400 \\
\hline$\varepsilon_{\text {theo }}\left(\mathrm{M}^{-1} \mathrm{~cm}^{-1}\right)$ & 81300 & 62600 & 66000 & - & 63300 & 93000 & 46700 \\
\hline$\Delta E_{\exp }(\mathrm{eV})$ & 2.36 & 2.03 & 2.50 & 2.50 & 2.15 & 2.12 & 2.59 \\
\hline$\Delta E_{\text {theo }}(\mathrm{eV})$ & 2.51 & 2.22 & 2.61 & - & 2.29 & 2.22 & 2.64 \\
\hline Compounds & $\mathbf{H}$ & $\mathbf{I}$ & $\mathbf{J}$ & $\mathbf{K}$ & $\mathbf{L}$ & $\mathbf{M}$ & $\mathbf{N}$ \\
\hline$\lambda_{\exp }(\mathrm{nm})$ & 490 & 475 & 526 & 467 & 467 & 558 & 501,587 \\
\hline$\lambda_{\text {theo }}(\mathrm{nm})$ & 477 & - & 506 & 487 & 487 & 550 & 517,656 \\
\hline$\varepsilon_{\exp }\left(\mathbf{M}^{-1} \mathrm{~cm}^{-1}\right)$ & 45100 & 43200 & 61600 & 49600 & 47300 & 55100 & 51300,56000 \\
\hline$\varepsilon_{\text {theo }}\left(\mathrm{M}^{-1} \mathrm{~cm}^{-1}\right)$ & 54400 & - & 68600 & 72600 & 72700 & 96200 & 70800,8900 \\
\hline$\Delta E_{\exp }(\mathrm{eV})$ & 2.53 & 2.61 & 2.36 & 2.65 & 2.65 & 2.22 & 2.11 \\
\hline$\Delta E_{\text {theo }}(\mathrm{eV})$ & 2.60 & - & 2.22 & 2.55 & 2.55 & 2.25 & 1.89 \\
\hline
\end{tabular}


comparable, because the two dyes possessed the same electron donor.

Among the different electron acceptors, the most interesting one is undoubtedly EA12, which enables the design of a dye (N) exhibiting two ICT bands located at 510 and $587 \mathrm{~nm}$ respectively. For comparison, EA5 which is the strongest electron acceptor of the series could only furnish a dye (B) with an absorption maximum at $610 \mathrm{~nm}$, and therefore only shifted by about $20 \mathrm{~nm}$ compared to dye $\mathbf{N}$. Based on previous reports devoted for tetranitrofluorene-based dyes, the presence of the two intense ICT bands detected in the UV-visible absorption spectrum of $\mathbf{N}$ can be assigned to a significant intramolecular charge transfer occurring in the ground state. ${ }^{86}$ In particular, due to the presence of four electron withdrawing nitro groups onto TNF, numerous mesomeric forms can be written, differing by the length of the $\pi$-conjugated spacer between the nitro and the amino groups (see Fig. 4).

As anticipated, the highest molar extinction coefficients could be found for the four dyes bearing the strongest electron acceptors (EA5, EA8, EA11 and EA12), namely dyes B, J, M and $\mathbf{N}$. By increasing the electron acceptor strength, the oscillator strength is logically increased, enhancing the molar extinction coefficients (see Fig. S1, ESI $\dagger$ ).

A comparison with the simulated UV-visible absorption spectra in dichloromethane revealed the calculations to give absorption maxima to be in perfect agreement with the experimental one (see Fig. S1 and S2, ESI $\dagger$ ). Finally, considering that 2 isomers (D and I) could be separated from their respective mixtures ( $\mathbf{C}$ and H), a comparison between the absorption spectra of the isolated isomer and the mixture could be established (see Fig. 5). Interestingly, if the absorption spectrum of $\mathbf{C}$ perfectly superimposed that of $\mathbf{D}$, a completely different behavior was found for $\mathbf{H}$ and $\mathbf{I}$, the ICT band of I being blue-shifted by $14 \mathrm{~nm}$ (476 $\mathrm{nm} v s$. $490 \mathrm{~nm}$ for $\mathbf{H}$ ). Considering that the isomer I is less conjugated than its analogue, on the basis of the UV-visible absorption spectra, it can be confidently proposed that $\mathbf{I}$ is the s-cis isomer of $\mathbf{H}$.

Additionally, in this configuration, the s-cis configuration imposes an internal torsion inside the molecules due to the steric hindrance generated by the donor and the acceptor so that a reduction of the conjugation between the two partners is
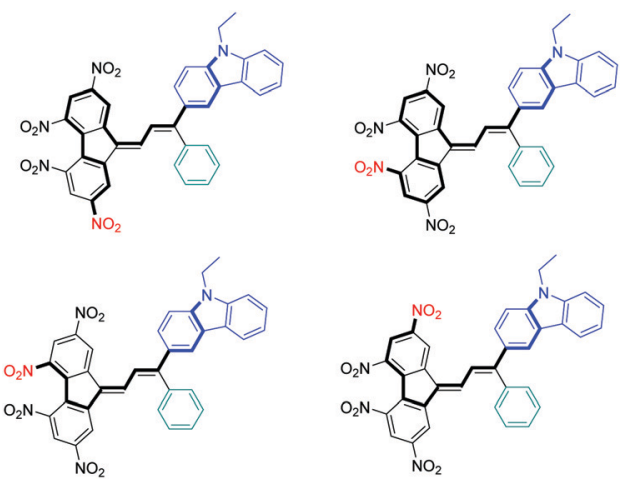

Fig. 4 Different mesomeric forms supporting the presence of two ICT bands for the TNF-based dye $\mathbf{N}$.

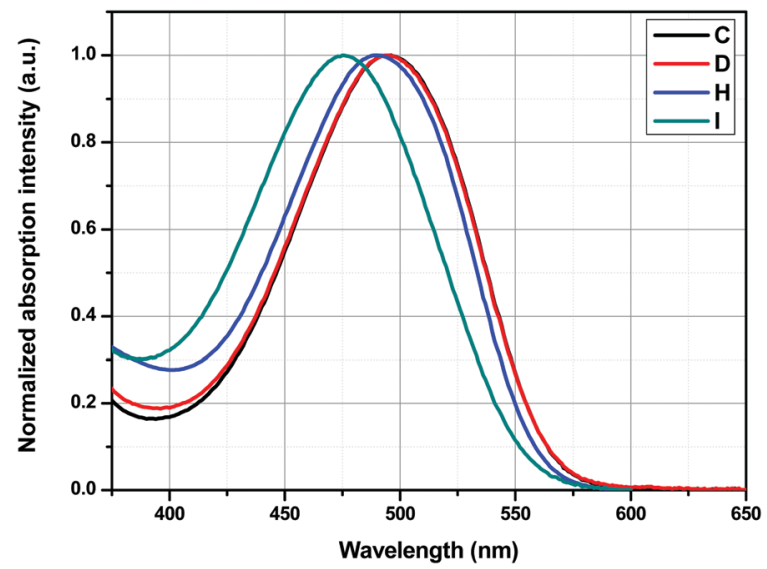

Fig. 5 Comparison of the UV-visible absorption spectra of $\mathbf{C} / \mathbf{D}$ and $\mathbf{H} / \mathbf{I}$ in chloroform.

logically observed. Considering that severe variations of the absorption maxima were found by varying the electronwithdrawing groups, the experimental behavior observed for dyes $\mathbf{A}-\mathbf{N}$ was rationalized by theoretical calculations.

\section{B3. Theoretical calculations}

The energy levels of the highest occupied molecular orbital (HOMO) and the lowest unoccupied molecular orbital (LUMO) were determined by theoretical calculations and a representative set of the electronic distribution is provided in Fig. 6. As evidenced in Fig. 6, a HOMO energy level specifically localized on the carbazole group and a LUMO energy level comprising both the acceptor and the lateral phenyl ring could be found for all dyes. While examining the energy levels of both the HOMOs and LUMOs of all dyes, almost no variation of the HOMO level was found, consistent with a localization of the HOMO onto the carbazole moiety (see Table 2). Conversely, major differences could be found for the positions of the LUMO levels, resulting from their localization onto the acceptor moieties. As a result of this, the variation of the HOMO-LUMO gap only originates from the variation of the positions of the LUMO levels. More precisely, by improving the electron-accepting ability, the LUMO level is stabilized, decreasing the HOMO-LUMO gap.

\section{B4. Solvatochromism}

Push-pull dyes are compounds that are highly sensitive to their environment (polarity, and polarizability of the solvents) and position of the ICT bands can drastically vary with the solvent effects. $^{87,88}$ Generally, for push-pull dyes, both HOMO and LUMO energy levels are precisely localized onto two different parts of the molecule. In the present case, a positive solvatochromism is typically observed, evidencing an important charge redistribution upon photoexcitation and a dipole moment larger in the excited state than in the ground state. This behavior is typically found for push-pull dyes exhibiting a relatively small dipole moment in the ground state, which is achievable by separating the donor from the acceptor by an elongated spacer. ${ }^{89-93}$ To investigate the solvatochromic 

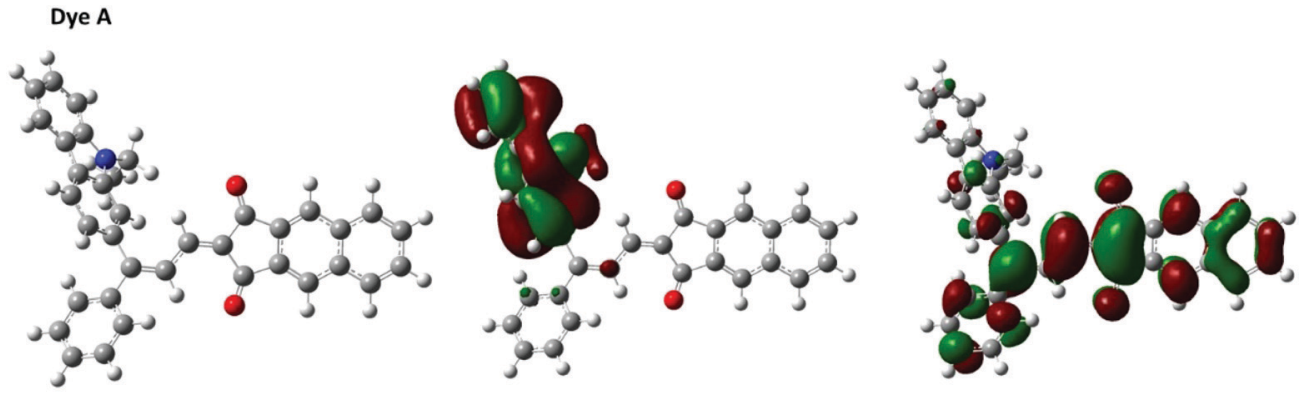

Dye C
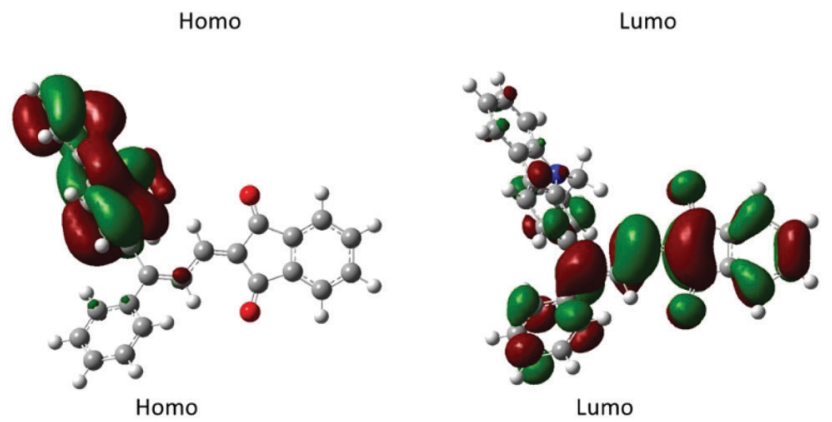

Dye G
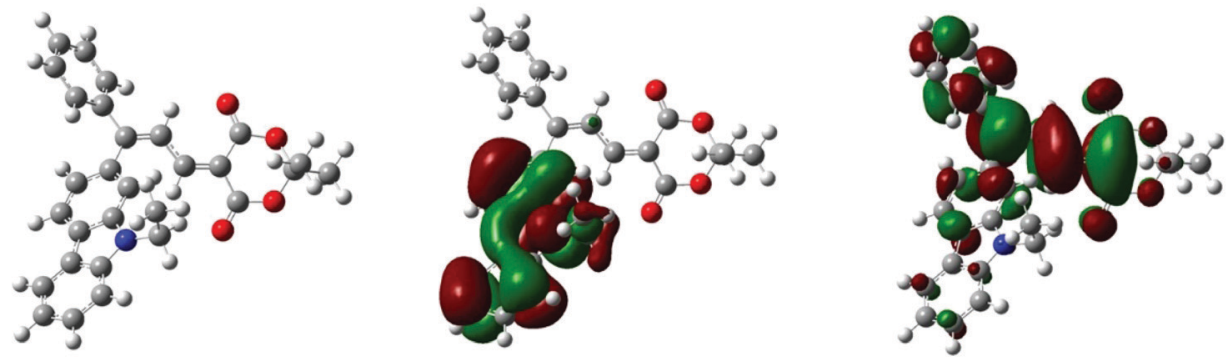

Homo

Lumo

Fig. 6 Optimized geometries and HOMO/LUMO electronic distributions of dyes A, C and G.

Table 2 Theoretical positions of the HOMO and LUMO energy levels

\begin{tabular}{lllllll}
\hline Compounds & A & B & C/D & E & F & G \\
\hline HOMO (eV) & -5.55 & -5.48 & -5.56 & -5.71 & -5.83 & -5.69 \\
LUMO (eV) & -2.72 & -3.17 & -2.64 & -3.06 & -3.27 & -2.78 \\
\hline Compounds & H/I & J & K & L & M & N \\
\hline HOMO (eV) & -5.64 & -5.71 & -5.66 & -5.67 & -5.95 & -5.90 \\
LUMO (eV) & -2.79 & -2.99 & -2.72 & -2.72 & -3.33 & -3.91
\end{tabular}

properties of dyes, numerous solvent polarity scales have been developed over the years and the Kamlet-Taft's, ${ }^{94}$ DimrothReichardt's, ${ }^{95}$ Lippert-Mataga's, ${ }^{96}$ Catalan's, ${ }^{97,98}$ KawskiChamma-Viallet's, ${ }^{99}$ McRae's, ${ }^{100}$ Suppan's, ${ }^{101}$ and Bakhshiev's ${ }^{102}$ scales can be cited as the most popular ones. Investigations of the solvatochromic properties of dyes $\mathbf{A}-\mathbf{N}$ were carried out in 23 solvents of different polarities and changes in the longestwavelength absorption maxima $\lambda_{\max }$ for the 14 dyes are summarized in Table 3. First, the intramolecular nature of the charge transfer detected for all dyes was verified by realizing successive dilutions and linear plots could be obtained by measuring the absorbance $v s$. the dye concentration. This point being verified, the resulting data were evaluated by means of the different abovementioned empirical models. Interestingly, remarkable correlations were obtained on the Kamlet-Taft and the Catalan scales as well as, to a lesser extent, on the Reichardt scale. In particular, for the Catalan, several parameters have been developed such as the solvent polarizability (SP), the solvent dipolarity (SdP) and the solvent polarity/polarizability (SPP) parameters. ${ }^{103-105}$ In this work, the best correlations were obtained with the Catalan SPP parameters taking into account the polarity/polarizability of the solvents. This is also this interaction, which is considered by the two other solvatochromic scales, namely the Kamlet-Taft and the Reichardt models. Therefore, the solvent-solute interactions are mainly governed by the polarity/polarizability of the solvents, which was confirmed by three polarity scales based on these interactions. Among all dyes, the best correlations were obtained for dyes $\mathbf{B}$ or $\mathbf{K}$, as shown in the Fig. 7 . 
Table 3 Summary of the optical properties of compounds $\mathbf{A}-\mathbf{H}$ in solvents of various natures

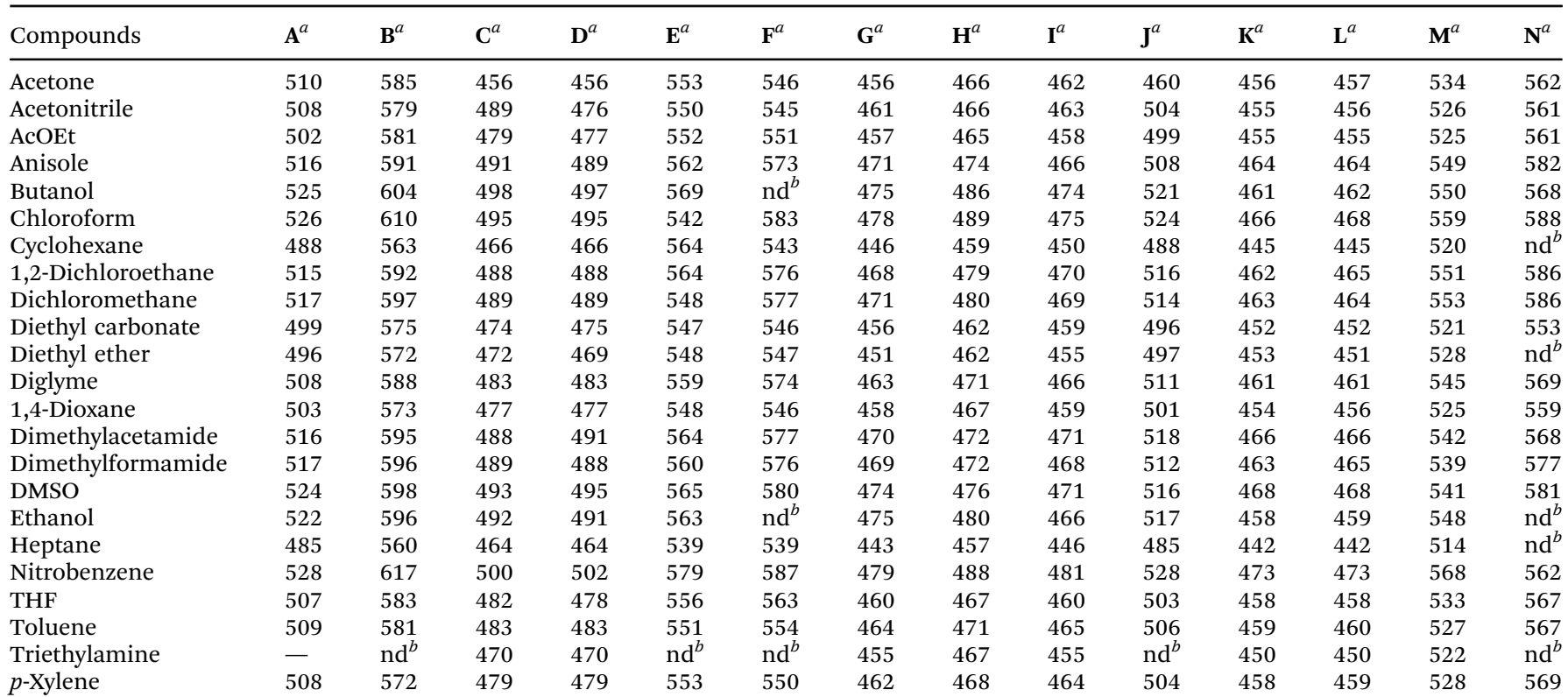

${ }^{a}$ Position of the ICT bands are given in nm. ${ }^{b}$ nd: not determined.

For all dyes, negative slope lines were found for the linear regressions, irrespective of the polarity scales, indicative of positive solvatochromism. Considering that the absolute value of the slopes can provide information of the sensitivity of the dyes to the solvent polarity and thus of the charge redistribution upon excitation, a summary of the different negative slope lines is provided in Fig. 8. Interestingly, in the series of 12 dyes, three different behaviors could be detected. Thus, only dyes $\mathbf{E}, \mathbf{F}, \mathbf{H}$ and $\mathbf{N}$ differ from the others for which similar slopes were found for both the Kamlet-Taft or the Catalan plots. Comparison between $\mathbf{H}$ and $\mathbf{I}$ is particularly interesting since $\mathbf{I}$ is a pure isomer isolated from $\mathbf{H}$. Besides, a completely different behavior with regard to the solvent polarity was found, $\mathbf{H}$ exhibiting a lower sensitivity than $\mathbf{I}$. These results confirm that $\mathbf{I}$ is certainly the s-cis isomer, and that the internal torsion induced by the steric hindrance between the donor and the acceptor are
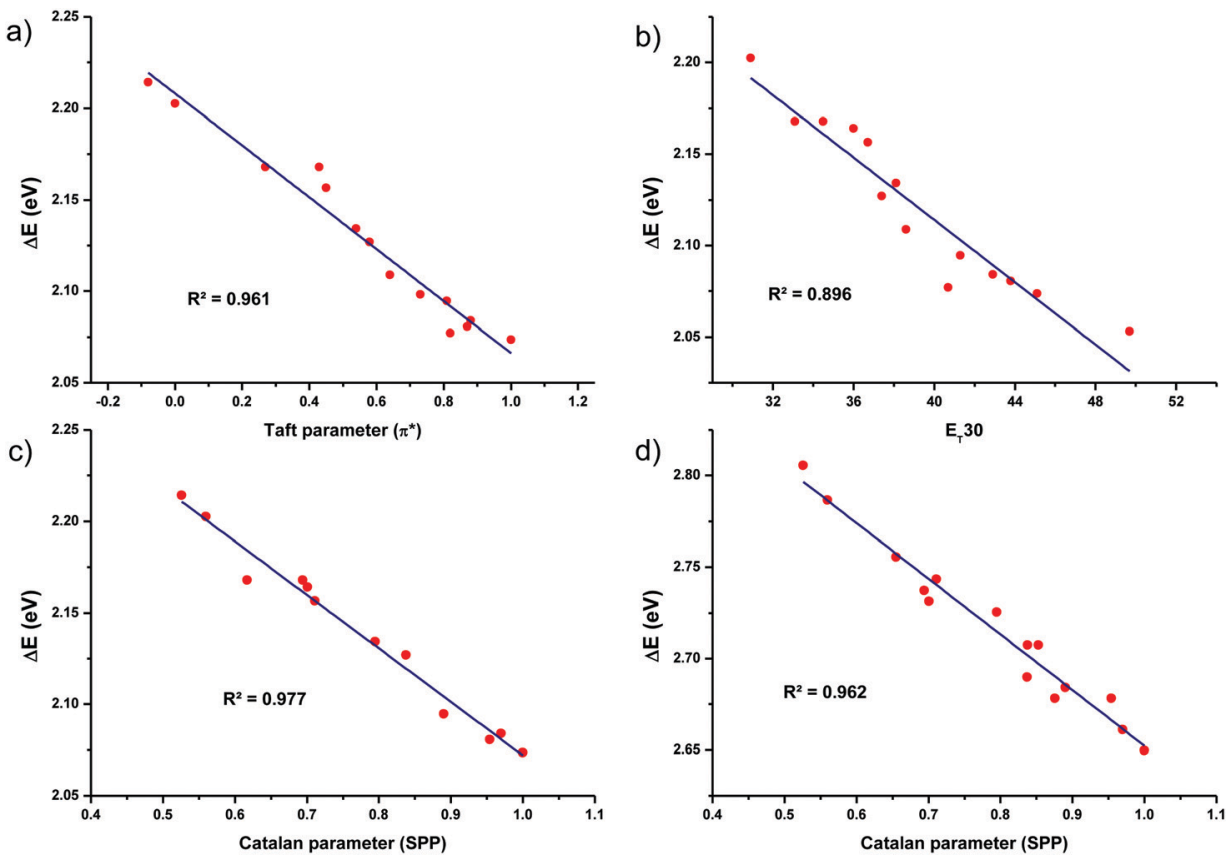

Fig. 7 Scatterplots with overlaid linear regression plots for dye B with (a) the Kamlet-Taft graph (b) the Reichardt graph (c) the Catalan graph and for dye $\mathbf{K}(\mathrm{d})$ the Catalan graph. 

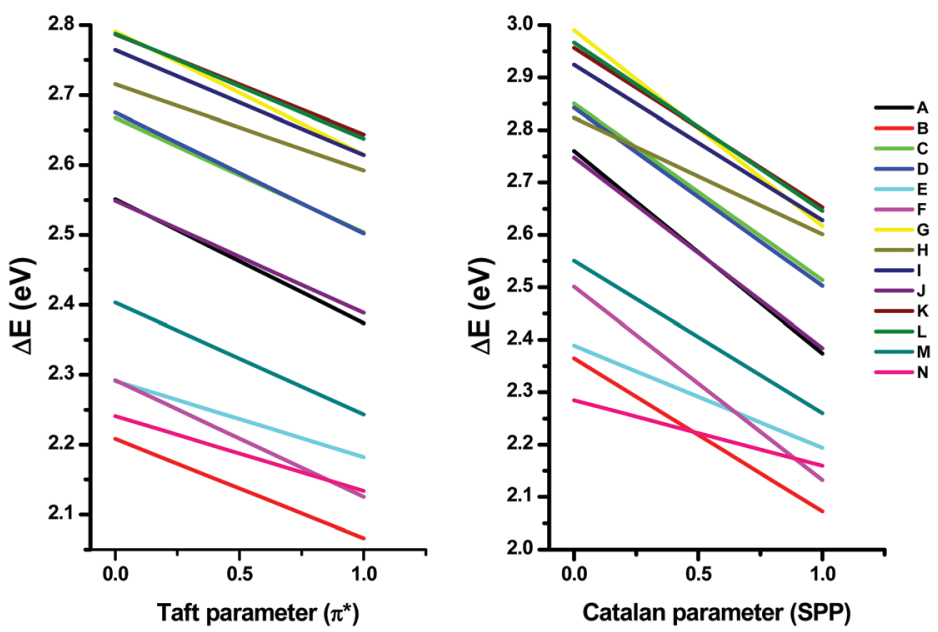

Fig. 8 Variation of the positions of the charge transfer band with the Kamlet-Taft and Catalan empirical parameters for dyes $\mathbf{A}-\mathbf{N}$.

drastically modified by the polarity of the solvents. Conversely, C and its pure isomer $\mathbf{D}$ show similar slopes in both plots. Based on the NMR experiments, similarity of behaviors between $\mathbf{C}$ and $\mathbf{D}$ arises from the fact that $\mathbf{D}$ is mostly composed of $\mathbf{C}$, resulting in a minor contribution of the second isomer on the optical properties. A lower sensitivity to the solvent polarity is also found for dyes $\mathbf{E}$ and $\mathbf{N}$ what is counter-intuitive considering that these two dyes possess strong electron acceptors. Finally, the most negative slopes were determined for dye $\mathbf{F}$ bearing $\mathbf{E A} \mathbf{3}$ as the acceptor. This pronounced sensitivity to the solvent polarity can be assigned to the presence of the numerous cyano groups on EA3, favoring a major redistribution of the electronic density upon excitation when highly polar solvents are used.

\section{B5. Photoluminescence spectroscopy}

The emission properties of all dyes were examined in chloroform as the solvent. Since almost all compounds were fluorescent, and were therefore not sensitive to oxygen, all experiments were carried out in air. Most of the dyes were photoluminescent so that a Stokes shift could be determined for most of the dyes. In addition, as shown in Fig. 9, by determining the crossing point between the UV-visible and the fluorescence spectra of

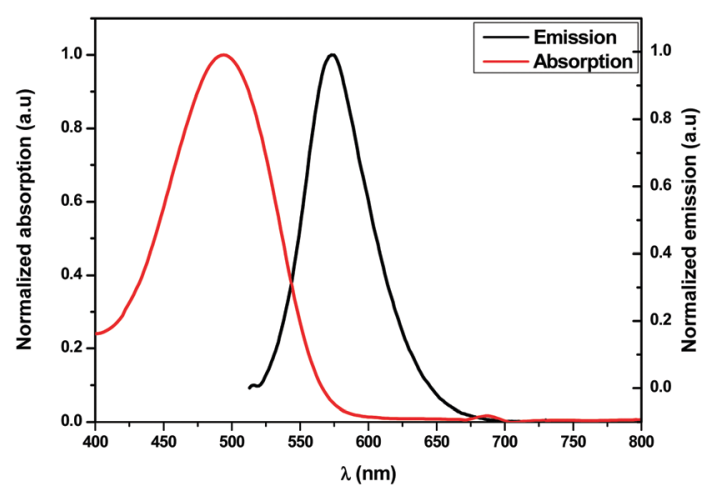

Fig. 9 Normalized absorption and emission intercept curves of dye $\mathbf{D}$ in chloroform. each dye, energy of the first singlet excited state $\left(E_{\mathrm{S} 1}\right)$ could be determined. All data are summarized in Table 4.

Carbazoles are known to be fluorescent compounds which explains why the different dyes were emissive. ${ }^{106-108}$ Only dye $\mathbf{N}$ comprising a TNF moiety as the acceptor was not emissive. The lack of photoluminescence of compound $\mathbf{N}$ can be attributed to the presence of the nitro groups, well-known to efficiently quench the photoluminescence of luminescent compounds. ${ }^{109,110}$ For all dyes, Stokes shift ranging from $50 \mathrm{~nm}$ for compound $\mathbf{B}$ to $97 \mathrm{~nm}$ for compound $\mathbf{M}$ could be determined. The largest Stokes shift was obtained for dye $\mathbf{M}$ comprising the 2-dicyanomethylidene-3-cyano-4,5,5-trimethyl2,5-dihydrofuran (TCF) group as the acceptor. ${ }^{111,112}$ These large Stokes shifts are indicative of a significant electronic redistribution between the ground state and the excited state. ${ }^{113}$ Additionally, the fluorescence of the indane compounds (comprising EA1-EA5 as the electron acceptors) seems to be highly dependent of the number of the cyano functions. Indeed, the Stokes shift of $\mathbf{F}$ was only $61 \mathrm{~nm}$ while a Stokes shift of $68 \mathrm{~nm}$ and 78/77 nm could be respectively determined for compounds $\mathbf{E}$ and $\mathbf{C} / \mathbf{D}$. In fact, a reduction of the Stokes shift with a redshift of the absorption maxima was observed, consistent with a decrease of the gap between the occupied and unoccupied orbitals. The same trend was observed while comparing the Stokes shifts between $\mathbf{B}$ and $\mathbf{E}$. Indeed, due to the improved electron-withdrawing ability of EA2 compared to EA5, a reduction of the Stokes shift was detected, going from $\mathbf{E}(68 \mathrm{~nm})$ to $\mathbf{B}(50 \mathrm{~nm})$.

\section{B6. Electrochemical properties}

All push-pull dyes were investigated by cyclic voltammetry (CV) in deaerated acetonitrile solutions. The selected set of voltammograms is shown in Fig. 9 and all CV curves are given in the ESI. $\uparrow$ The redox potentials of all compounds are summarized in the Table 5 in which the redox potentials are given against the half wave oxidation potential of the ferrocene/ferrocenium cation couple.

All the synthesized compounds exhibited irreversible singleelectron oxidation and single-electron reduction processes. Concerning the oxidation, all the push-pull molecules were 
Table 4 Fluorescence properties of the different compounds recorded in chloroform

\begin{tabular}{|c|c|c|c|c|c|c|c|}
\hline & $\mathbf{A}$ & $\mathbf{B}$ & C & D & $\mathbf{E}$ & $\mathbf{F}$ & G \\
\hline$\lambda_{\mathrm{ex}}(\mathrm{nm})$ & 526 & 610 & 495 & 495 & 575 & 583 & 479 \\
\hline$\lambda_{\mathrm{em}}(\mathrm{nm})$ & 612 & 660 & 573 & 572 & 643 & 644 & 562 \\
\hline Stokes shift $\left(\mathrm{cm}^{-1}\right)$ & 116279 & 200000 & 128205 & 129870 & 147059 & 163934 & 120482 \\
\hline \multirow[t]{2}{*}{$E_{\mathrm{S} 1}(\mathrm{eV})$} & 2.13 & 1.92 & 2.28 & 2.28 & 2.01 & 2.01 & 2.34 \\
\hline & $\mathbf{H}$ & I & $\mathbf{J}$ & $\mathbf{K}$ & $\mathbf{L}$ & $\mathbf{M}$ & $\mathbf{N}$ \\
\hline$\lambda_{\mathrm{ex}}(\mathrm{nm})$ & 490 & 475 & 526 & 467 & 467 & 558 & 587 \\
\hline$\lambda_{\mathrm{em}}(\mathrm{nm})$ & 570 & 570 & 600 & 555 & 550 & 655 & - \\
\hline Stokes shift (nm) & 125000 & 105263 & 135135 & 113636 & 120482 & 103093 & - \\
\hline$E_{\mathrm{S} 1}(\mathrm{eV})$ & 2.30 & 2.31 & 2.18 & 2.41 & 2.43 & 1.99 & \\
\hline
\end{tabular}

designed from the same donor moiety, namely the Cbz-BP, which explains that comparable oxidation potential are detected for all dyes, the oxidation of the carbazole group being detected around $750 \mathrm{mV}$ per $\mathrm{Fc}$ per $\mathrm{Fc}^{+}$. An oxidation process lowered by $c a .100 \mathrm{mV}$ was also observed for the compounds $\mathbf{L}$ and $\mathbf{M}$ and reduction of the oxidation potential can be explained by an oxidation process occurring on the amino group of the rhodanine acceptors.

Regarding the reduction process, most of the molecules are affected by a monoelectronic reduction located on the central double bound, slightly impacted by the acceptor moiety. Indeed, the stronger the electron withdrawing group, the stronger the cathodic shift. A relevant example of this can be obtained by comparing the reduction potentials of $\mathbf{M}$ and $\mathbf{I}$ (See Fig. 10 and Table 5). In this case, EA11 is more accepting than EA7, explaining the $200 \mathrm{mV}$ cathodic shift occurring during the reduction of the double bound.

Nonetheless, a reduction at a smaller cathodic potential was observed for $\mathbf{N}$, presumably resulting from the reduction of the

Table 5 Outline of the electrochemical properties of dyes $\mathbf{A}-\mathbf{N}$ compared with DFT calculations. $E_{\mathrm{ox}}$, correspond to all the oxidation potentials and $E_{\text {red }}$ the reduction potentials. $\Delta E_{\mathrm{el}}$ corresponds to the difference between the $\mathrm{HOMO}$ and the LUMO levels, electrochemically obtained. Finally, $\Delta E_{\text {th }}$ is the difference between the HOMO and LUMO levels, theoretically obtained. $\mathrm{Fc} / \mathrm{Fc}^{+}$was used as internal reference standard

\begin{tabular}{lllllll}
\hline & $\begin{array}{l}E_{\text {Ox onset }} \\
\text { Compounds }\end{array}$ & $\begin{array}{l}E_{\text {red onset }} \\
(\mathrm{V} \text { per Fc })\end{array}$ & $\begin{array}{l}E_{\text {HOMO }} \\
(\mathrm{eV})\end{array}$ & $\begin{array}{l}E_{\mathrm{LUMO}} \\
(\mathrm{eV})\end{array}$ & $\begin{array}{l}\Delta E_{\mathrm{el}}{ }^{a} \\
(\mathrm{eV})\end{array}$ & $\begin{array}{l}\Delta E_{\mathrm{th}}{ }^{b} \\
(\mathrm{eV})\end{array}$ \\
\hline $\mathbf{A}$ & 0.71 & -1.13 & -5.51 & -3.67 & 1.84 & 2.83 \\
$\mathbf{B}$ & 0.76 & -1.00 & -5.56 & -3.80 & 1.76 & 2.31 \\
$\mathbf{C}$ & 0.74 & -1.06 & -5.54 & -3.74 & 1.80 & 2.92 \\
$\mathbf{D}$ & 0.74 & -1.14 & -5.54 & -3.66 & 1.88 & 2.92 \\
$\mathbf{E}$ & 0.72 & -1.12 & -5.52 & -3.68 & 1.84 & 2.65 \\
$\mathbf{F}$ & 0.74 & -0.95 & -5.54 & -3.85 & 1.69 & 2.56 \\
$\mathbf{G}$ & 0.77 & -1.18 & -5.57 & -3.62 & 1.95 & 2.91 \\
$\mathbf{H}$ & 0.75 & -1.14 & -5.55 & -3.67 & 1.93 & 2.85 \\
$\mathbf{I}$ & 0.77 & -1.18 & -5.57 & -3.62 & 1.95 & 2.85 \\
$\mathbf{J}$ & 0.75 & -1.07 & -5.55 & -3.73 & 1.82 & 2.72 \\
$\mathbf{K}$ & 0.63 & -1.27 & -5.44 & -3.53 & 1.91 & 2.94 \\
$\mathbf{L}$ & 0.63 & -1.29 & -5.44 & -3.51 & 1.93 & 2.95 \\
$\mathbf{M}$ & 0.67 & -0.94 & -5.47 & -3.86 & 1.61 & 2.62 \\
$\mathbf{N}$ & 0.69 & -1.18 & -5.49 & -3.62 & 1.87 & 1.99
\end{tabular}

${ }^{a}$ Onset of the oxidation and reduction potentials versus ferrocene ( $E$ (onset) $v s . \mathrm{Fc}$ ). $E_{\mathrm{HOMO}}$ and $E_{\mathrm{Lumo}}$ were determined from the formulae: $E_{\mathrm{HOMO}}=-4.8-E_{\mathrm{Ox}} v s . \mathrm{Fc}$ and $E_{\mathrm{LUMO}}=-4.8-E_{\mathrm{red}} v s . \mathrm{Fc}^{113}{ }^{13} E_{\mathrm{HOMO}}$ and $E_{\mathrm{LUMO}}$ are given in $\mathrm{eV}$.

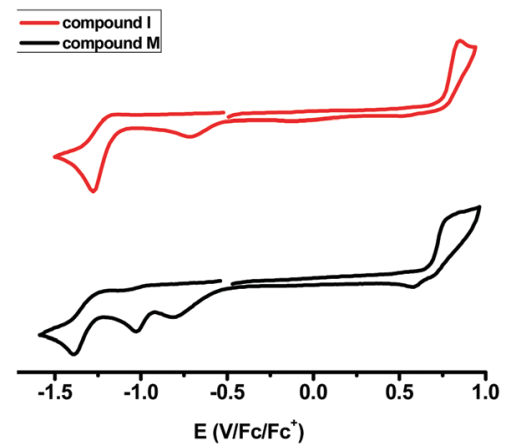

Fig. 10 Cyclic voltammograms of I (up) and $\mathbf{M}$ (down) in acetonitrile solutions $\left(10^{-3} \mathrm{M}\right)$ using tetrabutylammonium perchlorate $(0.1 \mathrm{M})$ as the supporting electrolyte. Scan rate: $100 \mathrm{mV} \mathrm{s}^{-1}$.

nitro groups prior to the central double bond. Reduction of the nitro groups is frequently observed in the case of poly(nitrofluorene) structures, explaining the difference of 200-500 mV observed between the reduction peak of this compound and that of the other dyes. ${ }^{114,115}$

Finally, by using the ferrocene $(\mathrm{Fc})$ ionization potential value as a standard and the equation established by Pommerehne et al., energy levels of the highest occupied molecular orbital (HOMO) and the lowest unoccupied molecular orbital (LUMO) could be estimated from the redox potentials (see Table 5). ${ }^{116}$

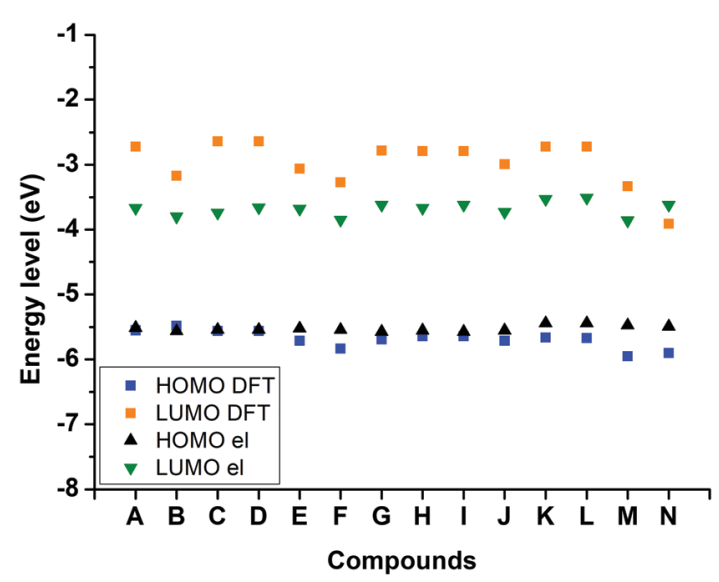

Fig. 11 Comparison between frontier orbital energy levels obtained from cyclic voltammetry and DFT calculations. 
Thanks to the determination of the HOMO and LUMO energy levels by electrochemistry, a comparison could be made between the experimental and the theoretical values of the two energy levels (see Fig. 11). If a clear difference can be noticed between the LUMO ${ }_{\mathrm{DFT}}$ and the $\mathrm{LUMO}_{\mathrm{el}}$, conversely, a good adequation between the theoretical and the experimental energy level of the HOMO orbital was found, as shown in the Fig. 11. Even if the position of the LUMO energy levels was overestimated by theoretical calculations, similar variations were found between the $\mathrm{LUMO}_{\mathrm{DFT}}$ and the $\mathrm{LUMO}_{\mathrm{el}}$. This difference can be attributed to the fact that influence of the solvent on the LUMO energy level is not fully considered in the calculations.

\section{Conclusions}

To conclude, a series of 12 push-pull dyes differing by the electron-acceptors have been designed and synthesized. Interestingly, the carbazole-based electron donor reported in this work has been synthesized for the first time according to a multistep synthesis. All dyes prepared using this electron donor proved to be soluble in most of the common organic solvents, even if electron acceptors such as (thio)barbituric acids and tetranitrofluorene derivatives well known to produce low soluble dyes have been used. By modifying the electron acceptors, a set of dyes absorbing over the whole visible range have been obtained. For all dyes, a positive solvatochromism could be determined, evidencing that the excited state of the dye is more polar than the ground state. If promising results have been obtained with this electron donor, the asymmetry of this elongated aldehyde is at the origin of the presence of numerous isomers. As a result of this, complicated NMR results were obtained. Future work will consist in developing a more symmetric structure bearing two carbazole moieties, to first simplify the NMR assignment, but also to improve the electron-donating ability of the donor.

\section{Conflicts of interest}

There are no conflicts to declare.

\section{Acknowledgements}

The authors thank Aix Marseille University and The Centre National de la Recherche Scientifique (CNRS) for financial support. The Agence Nationale de la Recherche (ANR agency) is acknowledged for its financial support through the PhD grants of Corentin Pigot (ANR-17-CE08-0010 DUALITY project) and Guillaume Noirbent (ANR-17-CE08-0054 VISICAT project).

\section{Notes and references}

1 P.-T. Chou and Y. Chi, Phosphorescent dyes for organic light-emitting diodes, Chem. - Eur. J., 2007, 13, 380-395.
2 S. Redon, G. Eucat, M. Ipuy, E. Jeanneau, I. GautierLuneau, A. Ibanez, C. Andraud and Y. Bretonnière, Tuning the solid-state emission of small push-pull dipolar dyes to the far-red through variation of the electron-acceptor group, Dyes Pigm., 2018, 156, 116-132.

3 J. M. Hancock, A. P. Gifford, Y. Zhu, Y. Lou and S. A. Jenekhe, n-Type conjugated oligoquinoline and oligoquinoxaline with triphenylamine end-groups: efficient ambipolar light emitters for device applications, Chem. Mater., 2006, 18, 4924-4932.

4 Y. Farré, M. Raissi, A. Fihey, Y. Pellegrin, E. Blart, D. Jacquemin and F. Odobel, Synthesis and properties of new benzothiadiazole-based push-pull dyes for p-type dye sensitized solar cells, Dyes Pigm., 2018, 148, 154-166.

5 Z. Parsa, S. Shahab Naghavi and N. Safari, Designing pushpull porphyrins for efficient dye-sensitized solar cells, J. Phys. Chem. A, 2018, 122, 5870-5877.

6 A. Yella, C.-L. Mai, S. M. Zakeeruddin, S. N. Chang, C.-H. Hsieh, C.-Y. Yeh and M. Graetzel, Molecular engineering of push-pull porphyrin dyes for highly efficient dyesensitized solar cells: the role of benzene spacers, Angew. Chem., Int. Ed., 2014, 53, 2973-2977.

7 F. Huo, H. Zhang, Z. Chen, L. Qiu, J. Liu, S. Bo and I. V. Kityk, Novel nonlinear optical push-pull fluorene dyes chromophore as promising materials for telecommunications, J. Mater. Sci.: Mater. Electron., 2019, 30, 12180-12185.

8 J. M. Raimundo, P. Blanchard, N. Gallego-Planas, N. Mercier, I. Ledoux-Rak, R. Hierle and J. Roncali, Design and synthesis of push-pull chromophores for second-order nonlinear optics derived from rigidified thiophene-basedconjugating spacers, J. Org. Chem., 2002, 67, 205-218.

9 N. Mohammed, A. A. Wiles, M. Belsley, S. S. M. Fernandes, M. Cariello, V. M. Rotello, M. M. M. Raposo and G. Cooke, Synthesis and characterisation of push-pull flavin dyes with efficient second harmonic generation (SHG) properties, RSC Adv. , 2017, 7, 24462-24469.

10 A. M. Thooft, K. Cassaidy and B. Van Veller, A small pushpull fluorophore for turn-on fluorescence, J. Org. Chem., 2017, 82, 8842-8847.

11 I. A. Karpenko, Y. Niko, V. P. Yakubovskyi, A. O. Gerasov, D. Bonnet, Y. P. Kovtun and A. S. Klymchenko, Push-pull dioxaborine as fluorescent molecular rotor: far-red fluorogenic probe for ligand-receptor interactions, J. Mater. Chem. C, 2016, 4, 3002-3009.

12 P. Xiao, F. Dumur, T.-T. Bui, X. Sallenave, F. Goubard, B. Graff, F. Morlet-Savary, J.-P. Fouassier, D. Gigmes and J. Lalevée, Panchromatic photopolymerizable cationic films using indoline and squaraine dyes based photoinitiating systems, ACS Macro Lett., 2013, 2, 736-740.

13 J. Zhang, N. Zivic, F. Dumur, P. Xiao, B. Graff, D. Gigmes, J.-P. Fouassier and J. Lalevée, A benzophenonenaphthalimide derivative as versatile photoinitiator for near UV and visible lights, J. Polym. Sci., Part A: Polym. Chem., 2015, 53, 445-451.

14 M.-A. Tehfe, F. Dumur, N. Vilà, B. Graff, C. R. Mayer, J.P. Fouassier, D. Gigmes and J. Lalevée, A multicolor 
photoinitiator for cationic polymerization and interpenetrated polymer network synthesis: 2,7-di-tertbutyldimethyl-dihydropyrene, Macromol. Rapid Commun., 2013, 34, 1104-1109.

15 P. Xiao, F. Dumur, D. Thirion, S. Fagour, A. Vacher, X. Sallenave, B. Graff, J.-P. Fouassier, D. Gigmes and J. Lalevée, Multicolor photoinitiators for radical and cationic polymerization: mono vs. poly functional thiophene derivatives, Macromolecules, 2013, 46, 6786-6793.

16 P. Xiao, M. Frigoli, F. Dumur, B. Graff, D. Gigmes, J.-P. Fouassier and J. Lalevée, J. Julolidine or fluorenone based push-pull dyes for polymerization upon soft polychromatic visible light or green light, Macromolecules, 2014, 47, 106-112.

17 M.-A. Tehfe, F. Dumur, B. Graff, F. Morlet-Savary, D. Gigmes, J.-P. Fouassier and J. Lalevée, Push-pull (thio)barbituric acid derivatives in dye photosensitized radical and cationic polymerization reactions under $457 / 473 \mathrm{~nm}$ Laser beams or blue LEDs, Polym. Chem., 2013, 4, 3866-3875.

18 P. Xiao, F. Dumur, B. Graff, L. Vidal, D. Gigmes, J.-P. Fouassier and J. Lalevée, Structural effects in the indanedione skeleton for the design of low intensity $300-500 \mathrm{~nm}$ light sensitive initiators, Macromolecules, 2014, 47, 26-34.

19 P. Xiao, F. Dumur, M.-A. Tehfe, D. Gigmes, J.-P. Fouassier and J. Lalevée, Red-light-induced cationic photopolymerization: perylene derivatives as efficient photoinitiators, Macromol. Rapid Commun., 2013, 34, 1452-1458.

20 F. Dumur, D. Gigmes, J.-P. Fouassier and J. Lalevée, Organic Electronics: an El Dorado in the quest of new photoCatalysts as photoinitiators of polymerization, Acc. Chem. Res., 2016, 49, 1980-1989.

21 D. Ravelli and M. Fagnoni, Dyes as visible light photoredox organocatalysts, ChemCatChem, 2012, 4, 169-171.

22 T. Le, T. Courant, J. Merad, C. Allain, P. Audebert and G. Masson, s-Tetrazine dyes: A facile generation of photoredox organocatalysts for routine oxidations, J. Org. Chem., 2019, 84, 16139-16146.

23 K. Fidaly, C. Ceballos, A. Falguières, M. Sylla-Iyarreta Veitia, A. Guy and C. Ferroud, Visible light photoredox organocatalysis: a fully transition metal-free direct asymmetric $\alpha$-alkylation of aldehydes, Green Chem., 2012, 14, 1293-1297.

24 V. da Gama Oliveira, M. Filomena do Carmo Cardoso and L. da Silva Magalhães Forezi, Organocatalysis: A brief overview on its evolution and applications, Catalysts, 2018, 8, 605.

25 F. Dumur, Recent advances on visible light photoinitiators of polymerization based on indane-1,3-dione and related derivatives, Eur. Polym. J., 2021, 143, 110178.

26 M. Abdallah, F. Dumur, B. Graff, A. Hijazi and J. Lalevée, High performance dyes based on triphenylamine, cinnamaldehyde and indane-1,3-dione derivatives for blue light induced polymerization for 3D printing and photocomposites, Dyes Pigm., 2020, 182, 108580.

27 K. Sun, C. Pigot, H. Chen, M. Nechab, D. Gigmes, F. Morlet-Savary, B. Graff, S. Liu, P. Xiao, F. Dumur and
J. Lalevée, Free radical photopolymerization and 3D printing using newly developed dyes: indane-1,3-dione and $1 \mathrm{H}-$ cyclopenta-naphthalene-1,3-dione derivatives as photoinitiators in three-component systems, Catalysts, 2020, 10, 463.

28 C. Pigot, G. Noirbent, D. Brunel and F. Dumur, Recent advances on push-pull organic dyes as visible light photoinitiators of polymerization, Eur. Polym. J., 2020, 133, 109797.

29 K. Sun, S. Liu, C. Pigot, D. Brunel, B. Graff, M. Nechab, D. Gigmes, F. Morlet-Savary, Y. Zhang, P. Xiao, F. Dumur and J. Lalevée, Novel push-pull dyes derived from $1 \mathrm{H}-$ cyclopenta $[b]$ naphthalene-1,3(2H)-dione as versatile photoinitiators for photopolymerization and their related applications: 3D-printing and fabrication of photocomposites, Catalysts, 2020, 10, 1196.

30 K. Sun, S. Liu, H. Chen, F. Morlet-Savary, B. Graff, C. Pigot, M. Nechab, P. Xiao, F. Dumur and J. Lalevée, Nethylcarbazole-1-allylidene-based push-pull dyes as efficient light harvesting photoinitiators for sunlight induced polymerization, Eur. Polym. J., 2021, 147, 110331.

31 C. Pigot, G. Noirbent, D. Brunel and F. Dumur, Recent advances on push-pull organic dyes as visible light photoinitiators of polymerization, Eur. Polym. J., 2020, 133, 109797.

32 A. Al Mousawi, C. Poriel, F. Dumur, J. Toufaily, T. Hamieh, J.-P. Fouassier and J. Lalevée, Zinc tetraphenylporphyrin as high performance visible-light photoinitiator of cationic photosensitive resins for LED projector 3D printing applications, Macromolecules, 2017, 50, 746-753.

33 M. Jaishankar, T. Tseten, N. Anbalagan, B. B. Mathew and K. N. Beeregowda, Toxicity, mechanism and health effects of some heavy metals, Interdiscip. Toxicol., 2014, 7, 60-72.

34 P. B. Tchounwou, C. G. Yedjou, A. K. Patlolla and D. J. Sutton, Heavy Metals Toxicity and the Environment, EXS, 2012, 101, 133-164.

35 K. S. Egorova and V. P. Ananikov, Toxicity of Metal Compounds: Knowledge and Myths, Organometallics, 2017, 36, 4071-4090.

36 F. Dumur, D. Bertin and D. Gigmes, Iridium(III) complexes as promising emitters for solid-state light-emitting electrochemical cells (LECs), Int. J. Nanotechnol., 2012, 9, 377-395.

37 F. Bureš, Fundamental aspects of property tuning in pushpull molecules, RSC Adv., 2014, 4, 58826-58851.

38 J. Kulhanek, F. Bures, O. Pytela, T. Mikysek, J. Ludvıkc and A. Ruzicka, Push-pull molecules with a systematically extended p-conjugated system featuring 4,5dicyanoimidazole, Dyes Pigm., 2010, 85, 57-65.

39 F. Dumur, D. Gigmes, J.-P. Fouassier and J. Lalevée, Organic Electronics: An El Dorado in the quest of new photoCatalysts as photoinitiators of polymerization, Acc. Chem. Res., 2016, 49, 1980-1989.

40 G. Noirbent, C. Pigot, T.-T. Bui, S. Péralta, M. Nechab, D. Gigmes and F. Dumur, Synthesis, optical and electrochemical properties of a series of push-pull dyes based on 
the 2-(3-cyano-4,5,5-trimethylfuran-2 $(5 \mathrm{H})$-ylidene)malononitrile (TCF) acceptor, Dyes Pigm., 2021, 184, 108807.

41 W. Cheng, H. Chen, C. Liu, C. Ji, G. Ma and M. Yin, Functional organic dyes for health-related applications, View, 2020, 1, 20200055.

42 J. Podlesný, O. Pytela, M. Klikar, V. Jelínková, I. V. Kityk, K. Ozga, J. Jedryka, M. Rudysh and F. Bureš, Small isomeric push-pull chromophores based on thienothiophenes with tunable optical (non)linearities, Org. Biomol. Chem., 2019, 17, 3623-3634.

43 J.-L. Wang, Q. Xiao and J. Pei, Benzothiadiazole-based D- $\pi$ A- $\pi$-D organic dyes with tunable band gap: synthesis and photophysical properties, Org. Lett., 2010, 12, 4164-4167.

44 M. P. Antony, T. Moehl, M. Wielopolski, J.-E. Moser, S. Nair, Y.-J. Yu, J.-H. Kim, K. Y. Kay, Y.-S. Jung, K. B. Yoon, C. Graetzel, S. M. Zakeeruddin and M. Graetzel, Long-Range p-Conjugation in Phenothiazinecontaining Donor-Acceptor Dyes for Application in DyeSensitized Solar Cells, ChemSusChem, 2015, 8, 3859-3868.

45 M. Katono, M. Wielopolski, M. Marszalek, T. Bessho, J. E. Moser, R. Humphry-Baker, S. M. Zakeeruddin and M. Grätzel, Effect of Extended $\pi$-Conjugation of the Donor Structure of Organic D-A- $\pi-\mathrm{A}$ Dyes on the Photovoltaic Performance of Dye-Sensitized Solar Cells, J. Phys. Chem. C, 2014, 118, 16486-16493.

46 A. Guerlin, F. Dumur, E. Dumas, F. Miomandre, G. Wantz and C. R. Mayer, Tunable optical properties of chromophores derived from oligo(para-phenylene vinylene), Org. Lett., 2010, 12, 2382-2385.

$47 \mathrm{H}$. Kuhn, Oscillator strength of absorption band in dye molecules, J. Chem. Phys., 1958, 29, 958.

48 J. Feng, Y. Jiao, W. Ma, M. K. Nazeeruddin, M. Grätzel and S. Meng, First principles design of dye molecules with ullazine donor for dye sensitized solar cells, J. Phys. Chem. C, 2013, 117, 3772-3778.

49 R. Thomas, A. Thomas, S. Pullanchery, L. Joseph, S. Mambully Somasundaran, R. Srinivasamurthy Swathi, S. K. Gray and K. George Thomas, Plexcitons: The role of oscillator strengths and spectral widths in determining strong coupling, ACS Nano, 2018, 12, 402-415.

50 R. Haraguchi, S.-G. Tanazawa, N. Tokunaga and S.-I. Fukuzawa, Palladium-Catalyzed Formylation of Alkenylzinc Reagents with S-(4-Nitrophenyl) Thioformate, Eur. J. Org. Chem., 2018, 1761-1764.

51 J. L. Diaz, B. Villacampa, F. Lopez-Calahorra and D. Velasco, Synthesis of polyconjugated carbazolyl-oxazolones by a tandem hydrozirconation-Erlenmeyer reaction. Study of their hyperpolarizability values, Tetrahedron Lett., 2002, 43, 4333-4337.

52 A. Bieliauskas, V. Getautis, V. Martynaitis, V. Jankauskas, E. Kamarauskas, S. Krikstolaityte and A. Sackus, Synthesis of electroactive hydrazones derived from carbazolyl-based 2propenals for optoelectronics, Synth. Met., 2013, 179, 27-33.

53 P. Ledwon, Recent advances of donor-acceptor type carbazole-based molecules for light-emitting applications, Org. Electron., 2019, 75, 105422.
54 F. Dumur, Recent advances on carbazole-based photoinitiators of polymerization, Eur. Polym. J., 2020, 125, 109503.

55 F. Dumur, Carbazole-based polymers as hosts for solutionprocessed organic light-emitting diodes: simplicity, efficacy, Org. Electron., 2015, 25, 345-361.

56 M. Hong, M. K. Ravva, P. Winget and J. L. Brédas, Effect of Substituents on the Electronic Structure and Degradation Process in Carbazole Derivatives for Blue OLED Host Materials, Chem. Mater., 2016, 28, 5791-5798.

57 F. Dumur, L. Beouch, S. Peralta, G. Wantz, F. Goubard and D. Gigmes, Solution-processed blue phosphorescent OLEDs with carbazole-based polymeric host materials, Org. Electron., 2015, 25, 21-30.

58 D. Tavgeniene, G. Krucaite, L. Peciulyte, G. Buika, E. Zaleckas, F. Dumur and S. Grigalevicius, New carbazole-indan-1,3-dione-based host materials for phosphorescent organic light emitting diodes, Mol. Cryst. Liq. Cryst., 2016, 640, 145-151.

59 R. Haraguchi, S.-G. Tanazawa, N. Tokunaga and S.I. Fukuzawa, Palladium-Catalyzed Formylation of Alkenylzinc Reagents with S-(4-Nitrophenyl) Thioformate, Eur. J. Org. Chem., 2018, 1761-1764.

60 J. L. Diaz, B. Villacampa, F. Lopez-Calahorra and D. Velasco, Synthesis of polyconjugated carbazolyl-oxazolones by a tandem hydrozirconation-Erlenmeyer reaction. Study of their hyperpolarizability values, Tetrahedron Lett., 2002, 43, 4333-4337.

61 A. Bieliauskas, V. Getautis, V. Martynaitis, V. Jankauskas, E. Kamarauskas, S. Krikstolaityte and A. Sackus, Synthesis of electroactive hydrazones derived from carbazolyl-based 2propenals for optoelectronics, Synth. Met., 2013, 179, 27-33.

62 G. Battistuzzi, S. Cacchi and G. Fabrizi, An efficient palladium-catalyzed synthesis of cinnamaldehydes from acrolein diethyl acetal and aryl iodides and bromides, Org. Lett., 2003, 5, 777-780.

63 E. Alacid and C. Najera, Acrolein diethyl acetal: A threecarbon homologating reagent for the synthesis of $\beta$ arylpropanoates and cinnamaldehydes by Heck reaction catalyzed by a Kaiser oxime resin derived palladacycle, Eur. J. Org. Chem., 2008, 3102-3106.

64 F. Dumur, C. R. Mayer, E. Dumas, F. Miomandre, M. Frigoli and F. Sécheresse, New chelating stilbazonium like dyes from Michler's ketone, Org. Lett., 2008, 10, 321-324.

65 K. Hara, T. Sato, R. Katoh, A. Furube, T. Yoshihara, M. Murai, M. Kurashige, S. Ito, A. Shinpo, S. Suga and H. Arakawa, Novel Conjugated Organic Dyes for Efficient Dye-Sensitized Solar Cells, Adv. Funct. Mater., 2003, 15, 246-252.

66 J. Francos, J. Borge, J. Diez, S. E. Garcia-Garrido and V. Cadierno, Easy entry to donor/acceptor butadiene dyes through a $\mathrm{MW}$-assisted $\mathrm{InCl}_{3}$-catalyzed coupling of propargylic alcohols with indan-1,3-dione in water, Catal. Commun., 2015, 63, 10-14.

67 J. Francos, S. E. Garcia-Garrido, J. Borge, F. J. Suarez and V. Cadierno, Butadiene dyes based on 3-(dicyano- 
methylidene)indan-1-one and 1,3-bis(dicyanomethylidene) indane: synthesis, characterization and solvatochromic behavior, RSC Adv., 2016, 6, 6858-6867.

68 J. E. Barnsley, W. Pelet, J. McAdam, K. Wagner, P. Hayes, D. L. Officer, P. Wagner and K. C. Gordon, When "donoracceptor" dyes delocalize: A spectroscopic and computational study of D-A dyes using "Michler's Base", J. Phys. Chem. A, 2019, 123, 5957-5968.

69 V. Cadierno, (E)-1,1,1-Trifluoro-6,6-bis(4-methoxyphenyl) hexa-3,5-dien-2-one, Molbank, 2020, 2020, M1120.

70 M.-A. Tehfe, F. Dumur, B. Graff, F. Morlet-Savary, D. Gigmes, J.-P. Fouassier and J. Lalevée, New push-pull dyes derived from Michler's ketone for polymerization reactions upon visible lights, Macromolecules, 2013, 46, 3761-3770.

71 H. Mokbel, F. Dumur, B. Graff, D. Gigmes, C. R. Mayer, J. Toufaily, T. Hamieh, J.-P. Fouassier and J. Lalevée, Michler's ketone as an interesting scaffold for the design of high-performance dyes in photoinitiating systems upon visible lights, Macromol. Chem. Phys., 2014, 215, 783-790.

72 J. Francos, J. Borge, J. Diez, S. E. Garcia-Garrido and V. Cadierno, Easy entry to donor/acceptor butadiene dyes through a $\mathrm{MW}$-assisted $\mathrm{InCl}_{3}$-catalyzed coupling of propargylic alcohols with indan-1,3-dione in water, Catal. Commun., 2015, 63, 10-14.

73 J. Francos, S. E. Garcia-Garrido, J. Borge, F. J. Suarez and V. Cadierno, Butadiene dyes based on 3-(dicyanomethylidene)indan-1-one and 1,3bis(dicyanomethylidene) indane: synthesis, characterization and solvatochromic behavior, RSC Adv., 2016, 6, 6858-6867.

74 S. Liu, H. Chen, Y. Zhang, K. Sun, Y. Xu, F. Morlet-Savary, B. Graff, G. Noirbent, C. Pigot, D. Brunel, M. Nechab, D. Gigmes, P. Xiao, F. Dumur and J. Lalevée, Monocomponent photoinitiators based on benzophenone-carbazole structure for led photoinitiating systems and application on 3D printing, Polymers, 2020, 12, 1394.

75 K. Zhan and Y. Li, Visible-Light Photocatalytic E to Z Isomerization of Activated Olefins and Its Application for the Syntheses of Coumarins, Catalysts, 2017, 7, 337.

76 C. Pigot, G. Noirbent, S. Peralta, S. Duval, T.-T. Bui, P.H. Aubert, M. Nechab, D. Gigmes and F. Dumur, New push-pull dyes based on 2-(3-oxo-2,3-dihydro-1Hcyclopenta[ $[b]$ naphthalen-1-ylidene)malononitrile: An amine-directed synthesis, Dyes Pigm., 2020, 175, 108182.

77 C. Pigot, G. Noirbent, S. Peralta, S. Duval, M. Nechab, D. Gigmes and F. Dumur, Unprecedented nucleophilic attack of piperidine on the electron acceptor during the synthesis of push-pull dyes by a Knoevenagel reaction, Helv. Chim. Acta, 2019, 102, e1900229.

78 T. Landmesser, A. Linden and H.-J. Hansen, A novel route to 1-substituted 3-(dialkylamino)-9-oxo-9H-indeno[2,1-c]pyridine-4-carbonitriles, Helv. Chim. Acta, 2008, 91, 265-284.

79 S. Helmy, S. Oh, F. A. Leibfarth, C. J. Hawker and J. Read de Alaniz, Design and synthesis of donor-acceptor Stenhouse adducts: a visible light photoswitch derived from furfural, J. Org. Chem., 2014, 79, 11316-11329.

80 M. Gao, H. Su, Y. Lin, X. Ling, S. Li, A. Qin and B. Zhong Tang, Photoactivatable aggregation-induced emission probes for lipid droplets-specific live cell imaging, Chem. Sci., 2017, 8, 1763-1768.

81 Y. Cui, H. Ren, J. Yu, Z. Wang and G. Qian, An indanonebased alkoxysilane dye with second order nonlinear optical properties, Dyes Pigm., 2009, 81, 53-57.

82 A. S. Batsanov, M. R. Bryce, S. R. Davies, J. A. K. Howard, R. Whitehead and B. K. Tanner, Studies on $\pi$-acceptor molecules containing the dicyanomethylene group. X-ray crystal structure of the charge-transfer complex of tetramethyltetrathiafulvalene and 2,3-dicyano-1,4naphthoquinone: (TMTTF) $)_{3}-(\mathrm{DCNQ})_{2}, J$. Chem. Soc., Perkin Trans. 2, 1993, 313-319.

83 C. Pigot, G. Noirbent, T.-T. Bui, S. Péralta, D. Gigmes, M. Nechab and F. Dumur, Push-pull chromophores based on the naphthalene scaffold: Potential candidates for optoelectronic applications, Materials, 2019, 12, 1342.

84 C. Cao, X. Zhou, M. Xue, C. Han, W. Feng and F. Li, Dual near-infrared-emissive luminescent nanoprobes forratiometric luminescent monitoring of clo-in living organisms, ACS Appl. Mater. Interfaces, 2019, 11, 15298-15305.

85 D. F. Perepichka, I. F. Perepichka, O. Ivasenko, A. J. Moore, M. R. Bryce, L. G. Kuzmina, A. S. Batsanov and N. I. Sokolov, Combining high electron affinity and intramolecular charge transfer in 1,3-dithiole-nitrofluorene push-pull diads, Chem. - Eur. J., 2008, 14, 2757-2770.

86 D. F. Perepichka, I. F. Perepichka, O. Ivasenko, A. J. Moore, M. R. Bryce, L. G. Kuzmina, A. S. Batsanov and N. I. Sokolov, Combining high electron affinity and intramolecular charge transfer in 1,3-dithiole-nitrofluorene push-pull diads, Chem. - Eur. J., 2008, 14, 2757-2770.

87 A. S. Klymchenko, Solvatochromic and fluorogenic dyes as environment-sensitive probes: design and biological applications, Acc. Chem. Res., 2017, 50, 366-375.

88 P. D. Zoon and A. M. Brouwer, A push-pull aromatic chromophore with a touch of merocyanine, Photochem. Photobiol. Sci., 2009, 8, 345-353.

89 L. G. S. Brooker, A. C. Craig, D. W. Heseltine, P. W. Jenkins and L. L. Lincoln, Color and Constitution. XIII. Merocyanines, as Solvent Property Indicators, J. Am. Chem. Soc., 1965, 87, 2443-2450.

90 R. M. Hermant, N. A. C. Bakker, T. Scherer, B. Krijnen and J. W. Verhoeven, Systematic study of a series of highly fluorescent rod-shaped donor-acceptor systems, J. Am. Chem. Soc., 1990, 112, 1214-1221.

91 S. Arzhantsev, K. A. Zachariasse and M. Maroncelli, Photophysics of trans-4-(dimethylamino)-4-cyanostilbene and its use as a solvation probe, J. Phys. Chem. A, 2006, 110, 3454-3470.

92 J. Widengren and C. A. M. Seidel, Manipulation and characterization of photo-induced transient states of Merocyanine 540 by fluorescence correlation spectroscopy, Phys. Chem. Chem. Phys., 2000, 2, 3435-3441. 
93 M. Guillaume, V. Liegeois, B. Champagne and F. Zutterman, Time-dependent density functional theory investigation of the absorption and emission spectra of a cyanine dye, Chem. Phys. Lett., 2007, 446, 165-169.

94 M. J. Kamlet, J.-L. M. Abboud, M. H. Abraham and R. W. Taft, Linear solvation energy relationships. 23. A comprehensive collection of the solvatochromic parameters,.pi.*...alpha., and.beta., and some methods for simplifying the generalized solvatochromic equation, J. Org. Chem., 1983, 48, 2877-2887.

95 C. Reichardt, Solvatochromic Dyes as Solvent Polarity Indicators, Chem. Rev., 1994, 94, 2319-2358.

96 E. Z. Lippert, Dipolmoment und Elektronenstruktur von angeregten Molekülen, Naturforscher, 1955, 10a, 541-545, http://zfn. mpdl.mpg.de/data/Reihe_A/10/ZNA-1955-10a-0541.pdf.

$97 \mathrm{~J}$. Catalan, On the $\mathrm{E}_{\mathrm{T}}(30), \pi^{*}$, Py, $\mathrm{S}^{\prime}$, and SPP empirical scales as descriptors of nonspecific solvent effects, J. Org. Chem., 1997, 62, 8231-8234.

98 J. Catalan, V. Lopez, P. Perez, R. Matin-Villamil and J. G. Rodriguez, Progress towards a generalized solvent polarity scale: The solvatochromism of 2-(dimethylamino)7-nitrofluorene and its homomorph 2-fluoro-7-nitrofluorene, Liebigs Ann., 1995, 2, 241-252.

99 A. Kawski, Zur lösungsmittelabhängigkeit der wellenzahl von elektronenbanden lumineszierender moleküle und über die bestimmung der elektrischen dipolmomente im anregungszustand, Acta Phys. Pol., 1966, 29, 507-518.

100 E. G. McRae, Theory of solvent effects on molecular electronic spectra. frequency shifts, J. Phys. Chem., 1957, 61, 562-572.

101 P. Suppan, Solvent effects on the energy of electronic transitions: experimental observations and applications to structural problems of excited molecules, J. Chem. Soc. A, 1968, 3125-3133.

102 N. G. Bakshiev, Universal intermolecular interactions and their effect on the position of the electronic spectra of molecules in two component solutions, Opt. Spektrosk., 1964, 16, 821-832.

103 J. Catalan, Toward a generalized treatment of the solvent effect based on four empirical scales: dipolarity ( $\mathrm{SdP}, \mathrm{a}$ new scale), polarizability (SP), acidity (SA), and basicity (SB) of the medium, J. Phys. Chem. B, 2009, 113, 5951-5960.

104 J. C. del Valle, F. García Blanco and J. Catalán, Empirical parameters for solvent acidity, basicity, dipolarity, and

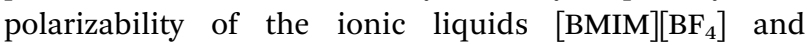
[BMIM][PF $]$, J. Phys. Chem. B, 2015, 119, 4683-4692.

105 J. Palomar, J. Z. Torrecilla, J. Lemus, V. R. Ferro and F. Rodriguez, Prediction of non-ideal behavior of polarity/polarizability scales of solvent mixtures by integration of a novel COSMO-RS molecular descriptor and neural networks, Phys. Chem. Chem. Phys., 2008, 10, 5967-5975.

106 H. Zhu, J. Huang, L. Kong, Y. Tian and J. Yang, Branched triphenylamine luminophores: aggregation-induced fluorescence emission, and tunable near-infrared solidstate fluorescence characteristics via external mechanical stimuli, Dyes Pigm., 2018, 151, 140-149.

107 M. Abdallah, D. Magaldi, A. Hijazi, B. Graff, F. Dumur, J.-P. Fouassier, T.-T. Bui, F. Goubard and J. Lalevée, Development of new high performance visible light photoinitiators based on carbazole scaffold and their applications in 3D printing and photocomposite synthesis, J. Polym. Sci., Part A: Polym. Chem., 2019, 57, 2081-2092.

108 A. Al Mousawi, P. Garra, F. Dumur, T.-T. Bui, F. Goubard, J. Toufaily, T. Hamieh, B. Graff, D. Gigmes, J.-P. Fouassier and J. Lalevée, Novel carbazole skeleton-based photoinitiators for LED polymerization and led projector 3D printing, Molecules, 2018, 22, 2143.

109 S. Dhiman, G. Kumar, V. Luxami, P. Singh and S. Kumar, A stilbazolium dye-based chromogenic and red-fluorescent probe for recognition of 2,4,6-trinitrophenol in water, $\mathrm{New}$ J. Chem., 2020, 44, 10870-10877.

110 D. Dhingra, Bhawna, A. Pandey and S. Pandey, Fluorescence quenching by nitro compounds within a hydrophobic deep eutectic solvent, J. Phys. Chem. B, 2020, 124, 4164-4173.

111 M. Ipuy, Y.-Y. Liao, E. Jeanneau, P. L. Baldeck, Y. Bretonnière and C. Andraud, Solid State Red Biphotonic Excited Emission from Small Dipolar Fluorophores, J. Mater. Chem. C, 2016, 4, 766-779.

112 N. A. Derevyanko, A. A. Ishchenko and A. V. Kulinich, Deeply coloured and highly fluorescent dipolar merocyanines based on tricyanofuran, Phys. Chem. Chem. Phys., 2020, 22, 2748-2762.

113 T.-B. Ren, W. Xu, W. Zhang, X.-X. Zhang, Z.-Y. Wang, Z. Xiang, L. Yuan and X.-B. Zhang, A general method to increase Stokes shift by introducing alternating vibronic structures, J. Am. Chem. Soc., 2018, 140, 7716-7722.

114 T. Fuchigami, M. Atobe and S. Inagi, Fundamentals and Applications of Organic Electrochemistry: Synthesis, Materials, Devices, John Wiley \& Sons, 2014.

115 G. Noirbent and F. Dumur, Recent advances on nitrofluorene derivatives: Versatile electron acceptors to create dyes absorbing from the visible to the near and far infrared region, Materials, 2018, 11, 2425.

116 J. Pommerehne, H. Vestweber, W. Guss, R. F. Mahrt, H. Bässler, M. Porsch and J. Daub, Efficient Two Layer Leds on a Polymer Blend Basis, Adv. Mater., 1995, 7, 551-554. 